\title{
Miscel·lània
}

\author{
MARÍA LAURA ROSA ${ }^{1}$
}

\section{La fotografía feminista en la creación de otras imágenes de mujeres. Buenos Aires en 1980}

\author{
Feminist Photography in the Creation of Other Images \\ of Women. Buenos Aires in the 1980s
}

\section{RESUMEN}

El presente artículo se propone analizar proyectos fotográficos feministas que surgen en Buenos Aires (Argentina) durante 1980. Alicia D'Amico e Ilse Fusková son fotógrafas feministas que reflejan en sus trabajos las reivindicaciones de los movimientos de mujeres en los que participan. En un momento marcado por el final de la última dictadura argentina y el inicio de la recuperación democrática, estas artistas toman los cuestionamientos que las feministas viene realizando sobre las imágenes de las mujeres y desarrollan proyectos en donde la identidad está en construcción, rompiendo con los estereotipos femeninos circulantes.

Palabras clave: Fotografía feminista, Fotografía Contemporánea, Teoría feminista.

\section{Abstract}

The aim of this article is to analyse feminist photographic projects that emerged in Buenos Aires (Argentina) during 1980. Alicia D'Amico and Ilse Fusková are feminist photographers who reflect in their work the demands of the women's movements in which they participated. At a time characterised by the end of the last Argentine dictatorship and the beginning of the return to the democracy, these artists reflects in their works the questions that feminists have been asking about women's images and develop projects where identity is under construction, breaking with gender stereotypes.

Keywords: Feminist Photography, Contemporary Photography, Feminist Theory.

\section{Sumario}

1.- Introducción y especificidades metodológicas. 2.- Orígenes de la relación arte/ feminismo en Buenos Aires. 3.- 1982. Año clave para el arte feminista de Buenos Aires. 4.Una búsqueda de acercarse a la identidad a través del autorretrato. 5.- Conclusiones. 6.Referencias/Bibliografía 


\section{1.- Introducción y especificidades metodológicas}

La teoría feminista del arte cuenta con varias décadas de producción crítica y de revisión de los conceptos articuladores que forman el canon de la Historia del Arte. En el presente artículo parto de la siguiente premisa: los feminismos están formados por un sistema de ideas dominantes que no son homogéneas pero que conforman un campo de investigación artístico cultural de enorme riqueza. En consecuencia, uno de los conceptos que guía la metodología de investigación que empleo es el propuesto por la historiadora del arte inglesa Lisa Tickner a finales de los años 80 . Ella plantea tener una problemática feminista en mente para llevar los análisis y objetivos del feminismo político al ámbito de la investigación cultural. (Tickner,

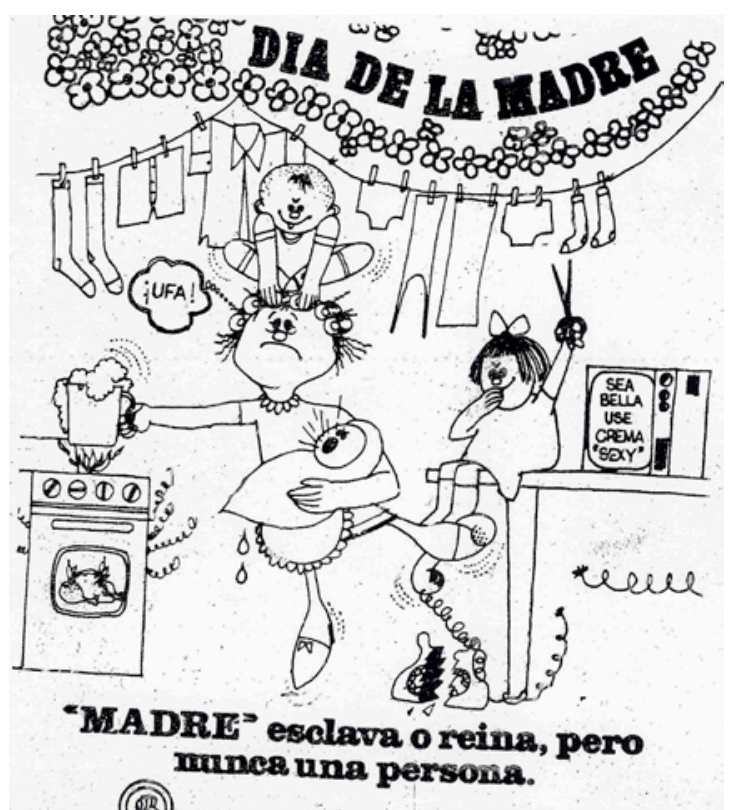

Unión Feminista Argentina

Imagen 1. Volante de UFA para el día de la madre de 1972. (Archivo Sara Torres)

1988:93) En este texto tomo dicho concepto para analizar los proyectos fotográficos que proponen artistas comprometidas con los movimientos de mujeres de la segunda ola porteña (Buenos Aires), a la vez que considero que toda producción artística se encuentra situada, es decir, se origina en un contexto social, político, económico y cultural particular, al que pretende transformar mediante acciones individuales y/o colectivas. En síntesis, la metodología empleada da cuenta de que las militancias feministas se llevan a cabo bajo una sangrienta dictadura militar que conduce a que éstas sean también prácticas de resistencia.

En 1970, se organiza en los salones del café Tortoni de la ciudad de Buenos Aires la Unión Feminista Argentina (UFA), en donde participan la cineasta María Luisa Bemberg, la fotógrafa Alicia D'Amico -en quien nos detendremos en este artículo-, la escritora Leonor Calvera, la directora de teatro Marta Miguelez y la poeta y escritora Hilda Rais, entre otras. Asimismo, en 1972, se conforma el Movimiento de Liberación Femenina (MLF) que instala con fuerza el debate sobre el aborto.

El modelo del ama de casa es expuesto críticamente por ambos grupos feministas, quienes visibilizan el trabajo agotador, no remunerado y depreciado de las tareas domésticas. Un temprano volante de UFA, de producción anónima, creado para el 
día de la madre de 1972 exhibe a una mujer preparando la comida frenéticamente, mientras atiende el teléfono con sus pies y se ocupa de los tres niños que intentaban hacer destrozos frente a la ropa lavada que ella acaba de colgar. A su lado, en una mesa, la TV transmite un aviso que la incita a mostrarse hermosa gracias al uso de la loción Sexy. En la parte inferior del dibujo, un epígrafe señala: «’Madre': esclava o reina, pero nunca una persona».

Esta pieza exhibe el trabajo simultáneo femenino frente al lineal masculino, si tomamos los conceptos desarrollados en la época por Christine Delphy (Delphy, 1980: 23-40). Vale decir, ante las mujeres que lavan a la vez que preparan la comida y cuidan de las/os niñas/os, los varones cumplen un horario exclusivo de trabajo en la esfera pública sin continuidad en la privada. En ese sentido, la producción visual de las feministas de UFA y del MLF es reflejo de los textos discutidos y de las problemáticas que emergen dentro de los grupos de concienciación.

María Luisa Bemberg se destaca por ser una de las primeras creadoras que relaciona los reclamos feministas con su producción fílmica dado que la integrantes de UFA impulsan a Bemberg a emplear la cámara para denunciar eventos de carácter sexista. Las reivindicaciones de UFA tal como constan en un artículo anónimo publicado en el diario La Opinión con el título «Inquietud de entidades locales por la urgente emancipación femenina» en donde se exige el «[...] esclarecimiento teórico de cómo funciona el aparato de opresión de la mujer y la denuncia de toda idea, sentimiento o conducta que mantenga o refuerce tal opresión [...]», así como también la «[...] revisión de libros de textos, y todo sistema de educación para eliminar la discriminación condicionante de los roles sexistas, desde el jardín de infantes [...]» (La Opinión, 1973:6), son los fundamentos de los cortos de Bemberg El mundo de la mujer (1972) y Juguetes (1978). En el primero de ellos, la cineasta filma la exposición Femimundo '72. Exposición Internacional de la mujer y su mundo que se lleva a cabo en el predio de exhibiciones de La Rural de la ciudad de Buenos Aires, busca mostrar cómo la mujer es objetualizada para el deseo heterosexual masculino a través de un extenso instrumental de belleza, que junto con los electrodomésticos, cumplen la función de mantenerla dentro de la esfera doméstica. Las demandas físicas se suman a las demandas psíquicas, el culto a la buena madre y esposa perpetúa una esclavitud que se vive como naturaleza y no como barbarie. De igual manera en Juguetes, Bemberg filma la Exposición Internacional del juguete, desarrollada seis años después en el mismo predio, donde muestra cómo las construcciones de los roles de género se afirman y continuan a través de los juegos que, desde la infancia, moldean a las niñas para la domesticidad y a los niños para la vida pública, los desafíos y las aventuras.

Tanto UFA como MFL realizan reuniones de concienciación y grupos de estudio y discusión de textos feministas. En ese sentido, es fundamental el ensayo de Simone de Beauvoir El segundo sexo, editado en Buenos Aires en 1954 por la editorial Psique, con traducción de Pablo Palant (Nari 2013: 291-307). También son leídas autoras extranjeras traducidas por nuestras feministas, entre ellas: Carla Lonzi, Shulamith Firestone, Kate Millet, Evelyn Reed, Anne Koedt quien analiza el mito del orgasmo vaginal o Christine Dupont, quien lleva a cabo una fuerte crítica a la domesticidad, 
entre otras. A la vez, nuestras feministas van desarrollando análisis propios que se ven reflejados en obras como las de Isabel Larguía, Mirta Henault, Leonor Calvera o el trabajo del colectivo formado por Inés Cano, María Inés Aldaburu, Hilda Rais y Nené Reinoso. Esta bibliografía da cuenta de fuertes cuestionamientos a la institución familiar, a la maternidad, al orden doméstico como único horizonte posible para las mujeres, a la construcción de imágenes femeninas en función del deseo heterosexual masculino, el cual cristaliza en un ideal de belleza que opera en complicidad con el mercado. El activismo callejero, a través de volantes que son entregados en la vía pública, convoca a las mujeres a sumarse a las agrupaciones feministas con objeto de su liberación sexual, política, económica y psicológica. También, ambos grupos feministas coinciden en la primera etapa de la publicación de la revista Persona, entre 1974 y1975. Alicia D'Amico junto a Sara Facio, reconocidas fotógrafas argentinas, realizan algunas fotografías para sus portadas, al igual que los retratos de varias entrevistadas, como el de la misma María Luisa Bemberg o el de la actriz Graciela Borges. Sin embargo, dicho material fotográfico no refleja investigaciones específicas sobre las construcciones visuales desde puntos de vista feministas, sino que conforma una interesante documentación de la revista a excepción de las tapas de los números $1 ; 2$ y 3, que podríamos interpretar como exponentes de las lectoras a las que estarían hablando estos movimientos: una mujer blanca caminando a su aire por la ciudad, una indígena con su niña/o sobre sus espaldas y a una niña blanca sobre el césped, consecutivamente. En síntesis, se dirigen a una mujer blanca, de clase media y urbana.

Asimismo, durante los años 60 y 70 del pasado siglo, la Argentina vive un momento de renovación y expansión de los mass-media, los que dejan de ser canales de comunicación y circulación de la información para transformarse en fuertes agitadores del consumo, empleando en numerosas ocasiones al cuerpo femenino para la venta de cualquier producto. Esto impacta sobre las mujeres del momento, ya que rápidamente devienen en blancos de la publicidad a través de la televisión y de numerosas publicaciones femeninas que, en el apogeo que vive el mercado editorial, circulan ampliamente. En este complejo entramado consumista, aparecen voces que rechazan el modelo sexista y cosificado que impone el mercado sobre el género. Es así como Catalina Trebisacce señala: «Las feministas locales de la primera mitad de la década del setenta se des-identificaron de los estereotipos de mujeres pasivas y hogareñas, y también lo hicieron del ideal cos(it)a-bella. Finalmente, también se extrañaron del imperativo de la maternidad como fundante de la identidad de toda mujer.» (Trebisacce 2013: 253)

En este contexto, no puedo soslayar las relaciones existentes entre los grupos de izquierda y los movimientos de mujeres. Las mismas se caracterizan por una fuerte complejidad debido a que las integrantes de las agrupaciones de izquierda también discuten problemáticas vinculadas con el sistema de desigualdad que impera sobre el género y, por esta razón, establecen vínculos con las feministas. Así señala Eva Rodríguez Agüero:

Si bien la idea de que la liberalización de las costumbres privadas buscaba seguir un modelo impuesto por las sociedades imperialistas lo cual atentó contra 
el establecimiento de puentes entre las luchas feministas y otras experiencias políticas, existieron algunos intentos de tender lazos entre mujeres feministas y mujeres políticas. Una de ellas fue la formación del Frente de Lucha por la Mujer, que aglutinaba a feministas y mujeres de partidos políticos de izquierda.

(Rodríguez Agüero 2013: 149)

Miembras de UFA prestan su espacio de encuentro para reuniones de mujeres de las agrupaciones de izquierda, manifestando lazos de sororidad. Sin embargo, la compleja trama en la que se insertan las agrupaciones feministas sufre el impacto del golpe de estado de marzo de 1976, que se extiende hasta la presidencia de Raúl Alfonsín en diciembre de 1983, momento en el que se vive un cambio estratégico en los movimientos de mujeres. Las feministas llevan adelante una relativa quietud dado que continuan desarrollando proyectos -el mismo corto Juguetes de Bemberg, la escritura del libro El género mujer de Leonor Calvera y la organización de congresos- que marcan los primeros años democráticos.

\section{2.- 1982. Año clave para el arte feminista de Buenos Aires}

El crecimiento alcanzado por los grupos feministas de Buenos Aires durante la primera mitad de los años 70 se ve afectado por el golpe militar del 24 de marzo de 1976 que obliga a sus integrantes a iniciar un exilio o un insilio-silencio interior-, aunque esto último fue relativamente corto. Como señalo más arriba, éstas consiguen reagruparse con el fin de llevar a cabo proyectos antes del final del gobierno de facto. En ese sentido, considero que el año 1982 es un momento clave para el arte feminista y en particular para la fotografía feminista, dado que coinciden dos propuestas fotográficas que reflexionan y buscan dar respuestas a las construcciones femeninas del imaginario heterosexual masculino argentino.

Por entonces, varias agrupaciones retoman el contacto a través de las actividades que planifica DIMA (Derechos Iguales para la Mujer Argentina). Una de ellas es el Primer Congreso Argentino La Mujer en el Mundo de Hoy -25 y 26 de octubre de 1982-, en las salas de ACARA de la ciudad de Buenos Aires, evento que promueve el encuentro de antiguas militantes con otras nuevas que se acercan. Allí, Alicia D'Amico comienza su proyecto sobre la mirada femenina a través del retrato fotográfico, así indica: «Ese mirar desde nuestra interioridad, de una manera nueva, puede dar como resultante una nueva estética que redefina el concepto de belleza existente.» (D'Amico, 1985). En simultáneo, Ilse Fusková crea la serie $E l$ Zapallo, unas de las piezas más importantes que tiene el arte feminista local. Dichas situaciones 'ponen sobre la mesa' propuestas artísticas críticas al patriarcado meses antes de la recuperación democrática. Me detendré en ellas y sus propuestas, así como también en la hipótesis de que estos trabajos cuestionan la identidad como un constructo fijo y estable.

Alicia D'Amico (Buenos Aires, 1933-2001) es una de las fotógrafas más importantes de la Argentina, fundadora del Consejo Argentino de Fotografía y cofundadora junto a Cristina Orive y a Sara Facio de la editorial La Azotea, pionera en fotolibros latinoamericanos. Es ampliamente reconocida por sus 
retratos a destacados escritores -como ser Alejandra Pizarnik, Olga Orozco, Pablo Neruda, Jorge Luis Borges, Julio Cortazar- y por su series publicadas en libros, especialmente Buenos Aires, Buenos Aires (1968), Humanario (1977), Podría ser yo. Los sectores urbanos en imágenes y palabras (1987), entre otros. Sin embargo, su implicancia con los movimientos de mujeres y su compromiso con el activismo feminista, que la lleva a importantes trabajos de investigación y documentación fotográfica, son escasamente exhibidos en vida de la fotógrafa y, tras su muerte, quedan en el olvido. En ese sentido, el proyecto que inicia durante el Primer Congreso Argentino La Mujer en el Mundo de Hoy (1982), cuyo nombre es Creación de la propia imagen, da cuenta de su interés por analizar la mirada femenina, así lo explica:

A fines de 1982 comencé una serie de trabajos a partir de la mirada femenina y su traslación a la fotografía. Los objetivos son múltiples. El primero de ellos, desarrollar la hipótesis de que existe una mirada femenina. Ese mirar desde nuestra interioridad, de una manera nueva, puede dar como resultante una nueva estética que redefina el concepto de belleza existente. El segundo objetivo es utilizar exhaustivamente la imagen fotográfica como vehículo de conocimiento y de autoconocimiento. Para ello trabajar con la propia imagen -retratos- es esencial por ser el referente directo de nuestra identidad. (D'Amico 1985)

Las cuestiones de la mirada femenina y de la identidad que plantea Creación de la propia imagen son trabajadas a través de los talleres Autorretrato -junto a Graciela Sikos (psicóloga)-, Identidad Femenina: Imagen y cambio; Mujer y Violencia; Mujer y Paz y La mujer y los mitos -realizados junto a Liliana Mizrahi (psicóloga)-desarrollados en el espacio Lugar de Mujer, en los Encuentros Feministas Latinoamericanos y del Caribe, así como también en otros centros feministas en donde D'amico es invitada, por ejemplo Isis en Italia o el grupo Identidad de la ciudad de Bahía Blanca (Argentina), ambos realizados en 1985. Dada la extensión del presente artículo, me centraré en los orígenes del proyecto a través de las fotografías que toma a las participantes del Primer Congreso Argentino La Mujer en el Mundo de Hoy y en el taller Autorretrato.

Respecto del origen de Creación de la propia imagen, la fotógrafa manifiesta:

Tenía la idea preconcebida de registrar mujeres como yo las veo, sin la cosa alambicada, sofisticada, mistificada e irreal que dan algunos medios. Me había propuesto hacer retratos como a mí me gustan, en 35 milímetros y luz natural y así los hice. Asistí al Congreso que se realizaba en un piso alto, desde una ventana entraba una hermosa luz que variaba según las diferentes horas del día. Cuando me parecía que la luz era adecuada, le pedía a cuanta mujer pasaba por ahí que posara para una foto. (Casares, 1983: 1)

Las críticas hacia la representación visual de la mujer son centrales en los feminismos argentinos de los años 70, y se reflejan en trabajos pioneros como los de Bemberg. En ese sentido, D’Amico continúa con esta línea de análisis en Creación de la propia imagen, el cual se enmarca en la noción de mujer nueva que éstos venían conceptualizando, la que refiere a aquellas que toman conciencia de 


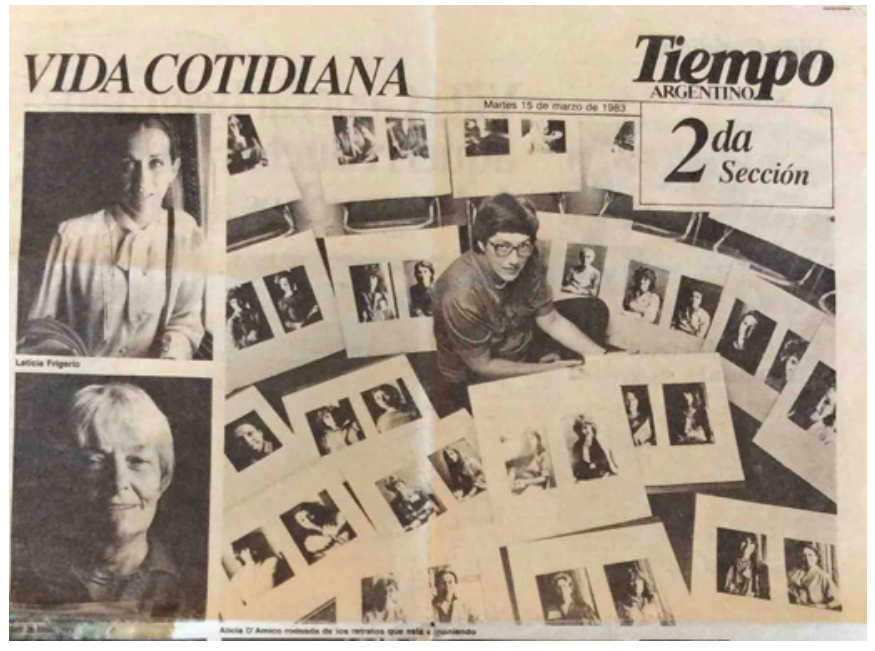

Imagen 2. Detalle del artículo de Casares, Giselle: "Alicia D’Amico: Luz natural a las mujeres" en Tiempo Argentino. Suplemento La Mujer, 15 de marzo de 1983, pp. 1-2. (Archivo Graciela Sikos)

su opresión dentro del sistema patriarcal, y por tanto, buscan ser protagonistas de sus propias vidas, peleando por la igualdad de sus derechos. As su vez, Leonor Calvera expresa que este término enmascara una alusión a la izquierda. «En los 70 la izquierda planteaba la urgencia de cambios para un hombre nuevo. Otros hablaban de un mundo nuevo. Todo estaba por hacerse. Por eso nosotras planteábamos la mujer nueva, desde el lenguaje hacíamos un guiño a la izquierda.» (Calvera, 2019)

El proyecto de D'Amico busca capturar la singularidad de cada retratada la cual conforma la diversidad femenina que escapa a las reducciones y estereotipos circulantes. El factor que las aglutina es la conciencia del lugar diferencial que ocupan socialmente a causa de su género. Las feministas, quizás de una manera más sutil si se quiere, trasladan el activismo que practican antes del régimen de facto a las salas en donde se desarrolla el Primer Congreso Argentino La Mujer en el Mundo de Hoy, con el fin de seguir diseñando estrategias de lucha sin olvidar históricas reivindicaciones. En ese contexto D'Amico se propone investigar otras imágenes de mujer, las de sus compañeras que pelean por la patria potestad indistinta, por exigir que se pague el trabajo doméstico, por reclamar que las mujeres puedan ascender profesionalmente y no quedar limitadas ante el techo de cristal patriarcal -invisible pero contante- entre otras problemáticas por las que deciden reagruparse. Estos retratos -más de setenta-, sin retoques ni grandes escenarios de estudio, abren camino a trabajos más complejos que la fotógrafa organiza junto a la psicóloga Graciela Sikos empleando el formato de taller. Me refiero a Autorretrato, del que hablaremos más adelante.

Los retratos que toma D'Amico muestran a las mujeres relajadas, felices por el reencuentro -en un momento en que las reuniones son evitadas- o preocupadas por afrontar tiempos difíciles, aunque esperanzadas en que los cambios lleguen. La fotógrafa señala que: 


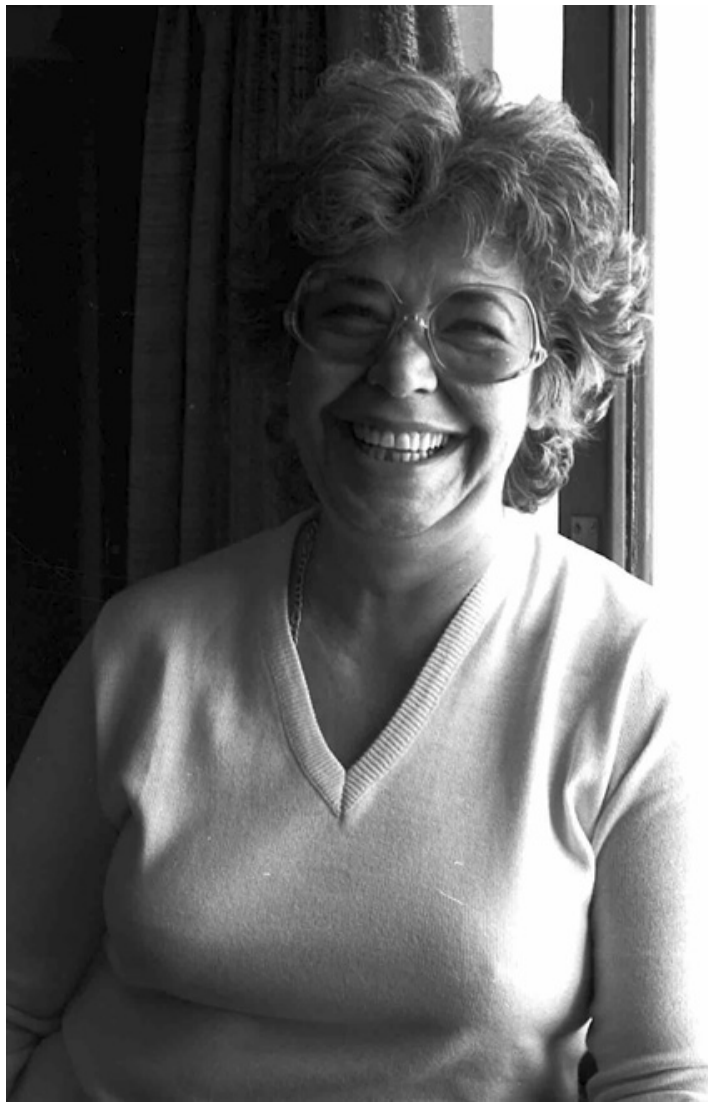

Imagen 3. Alicia D'Amico, Marysa Navarro, de la serie Creación de la propia imagen, 1982. Copias de escaneos de negativo original reproducción de contactos de negativo original, $35 \mathrm{~mm}$. (Archivo Alicia D'Amico)
Las caras -nuestras caras de mujeres reales- tienen todas las edades, traslucen sentimientos y pensamientos, carácter e inteligencia. Son seres humanos vitales $y$ conmovedores. Quise trasladar esa visión al fotografiar a mis hermanas. Las unifiqué por medio de una formalidad técnica. Todas están tomadas con luz natural, junto a una ventana, con un encuadre que sólo varía de la cabeza al medio cuerpo, La única exigencia fue que miraran a la cámara. Trabajé como me gusta, cámara $35 \mathrm{~mm}$ y lente normal. Trabajé con lo que me gusta: la gente. (D'Amico, 1983: 40)

La cuestión de la representación femenina no es un tema menor en un período en que se busca retomar problemáticas pendientes como las de la patria potestad indistinta, el divorcio vincular y el aborto. La difusión masiva de estereotipos que se reproducen a través de las imágenes de las mujeres, todo ello agravado por el alcance y el impacto de los mass-media en la población, plantea cambios urgentes. En marzo de 1983, D'Amico exhibe éstos retratos en el Centro de Información de las Naciones Unidas, ubicado en Buenos Aires. Como presentación de la exposición, la escritora María Elena Walsh expresa lo siguiente:

En un mundo saturado de falsas y aberrantes imágenes de mujeres, Alicia D'Amico las muestra en toda su desnudez espiritual. Con mirada de artista y un guiño de antropóloga, celebra a sus hermanas en un estilo ajeno a modas, trampas y artificios. [...] Pero falta todavía recorrer un largo camino para mirar a la mujer sin desagradarla con los filtros de la propaganda, la seudoidealización, la misoginia. [...] Queremos ser como somos doctor Freud. Así como nos ve Alicia D'Amico; dotadas de la única belleza que vale la pena, la de la verdad. (Casares, 1983: 1) 
Señalo más arriba que 1982 se vislumbra como un año clave para el arte feminista de Buenos Aires. En ese sentido, Creación de la propia imagen de Alicia D'Amico coincide con otra investigación del campo fotográfico, la que inicia Ilse Fusková a través de la serie El zapallo, de ella hablo a continuación.

Ilse Fusková (Buenos Aires, 1929) es conocida en Argentina por ser una importante activista lesbiana, fundamental en la lucha por la despatologización de la homosexualidad y por el derecho de este colectivo a tener una voz y una historia propias. Sin embargo, desde muy joven es intelectualmente inquieta, hecho que la lleva a desarrollar varias actividades en su vida. De padre alemán y madre checoslovaca, entre 1947 y 1952 estudia periodismo y se desempeña también como azafata. Colabora con reportajes y comentarios de cine en revistas como El Hogar, Chicas, Histonium, Mundo Argentino, Para Ti y Lyra hasta 1958, fecha en que inicia un largo retiro doméstico. En 1979, gracias a un anuncio aparecido en el periódico Buenos Aires Herald sobre la revista Persona -en esta etapa la revista es conducida por María Elena Oddone- Fusková conoce a la fundadora del MLF, hecho que la introduce en la bibliografía de teóricas como Simone de Beauvoir, Mary Daly, Carla Lonzi, Evelyn Reed, Victoria Sau, Valerie Sinason, Susan Sontag, entre otras, cuyos libros Oddone trae del exterior. La fotógrafa inicia un proceso de concienciación a través de lecturas y charlas feministas, así comenta: «El feminismo me salvó la vida, me hizo ver que las cosas que estaba viviendo, la profunda descalificación, falta de apoyo en la vida doméstica, familiar, eran parte de un sistema y cuando descubro eso salgo de una profundísima depresión. (...) Yo tengo clara conciencia que ponerme en contacto con esta ideología que explica lo que sucede con todas las mujeres, me salvó la vida.» (Fusková, 2004)

Por estos años, la fotógrafa vive el final de su matrimonio, lo que la lleva a una profunda crisis. Esta situación la lleva a detenerse en lo cotidiano desde una mirada más poética para hacer frente a su estado anímico. Ella recuerda esta etapa de su vida como uno de los motivos que origina su necesidad de regresar a la fotografía:

El zapallo era al final de mi matrimonio, yo estaba muy deprimida. Una de las cosas que me hacía bien era la belleza de la creación, una rosa que alguien me diera para el desayuno me podía salvar el día. Ir a hacer las compras, entrar en la verdulería y ver esos zapallos grandes cortados por la mitad, ahí veía un mundo de magia, llenos de telones dorados, de semillas, para mí eso era la magia. Yo no sé si alguna vez viste un zapallo así. Para mí era una cosa divina, llena de fertilidad y me dije, yo quiero hacer una serie de fotografías con esto. Me compré, entonces, el zapallo. (Ilse Fusková, 2008)

La conciencia de estar iniciando una nueva etapa -a sus cincuenta y tres años de edad- y la conformación de una mirada crítica atravesada por las lecturas y debates feministas, marcan su regreso a la fotografía, arte que no practica desde su última serie realizada a finales de los años 50, dado que se involucra por completo en la crianza de sus hijos. Así comenta: «Estaba cansada de la exigencia de lo doméstico. Tenía una buena cámara, era muy amiga de Grete Stern y Horacio Cóppola, y empecé a hacer fotos. Una amiga me contactó con la modelo del pintor Raúl Soldi. 


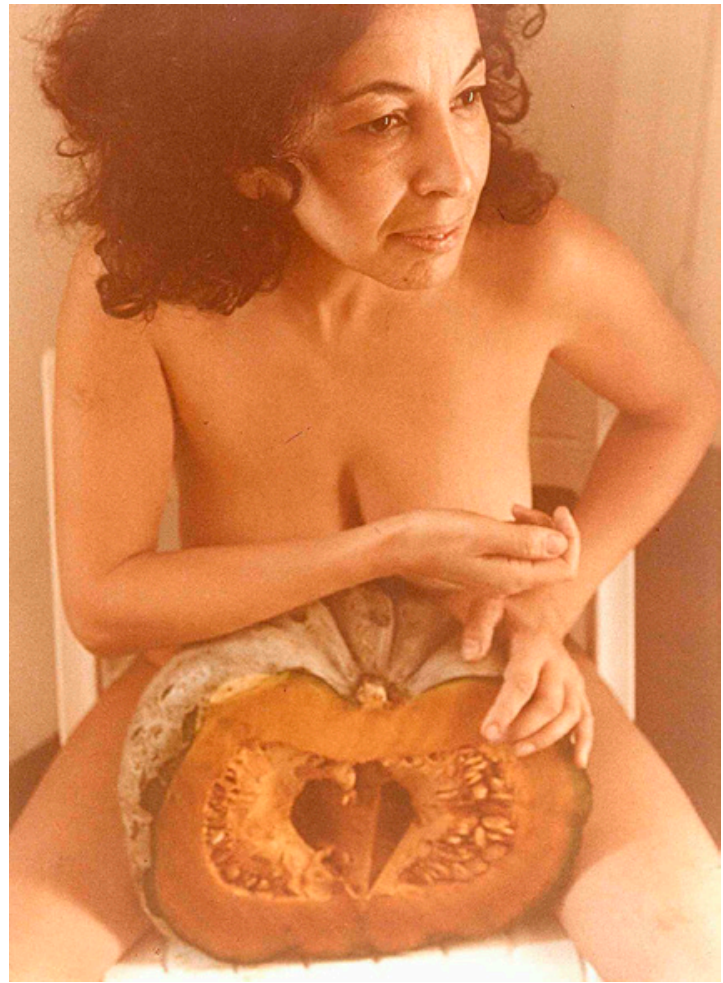

Imagen 4. Ilse Fusková. De la serie El zapallo, 1982, fotografía color, $35 \mathrm{~mm}$. (Archivo Ilse Fusková)
Para mí, el tema de la serie era la fertilidad, tanto a nivel biológico como a nivel cerebral.» (Ilse Fusková, 2008)

Doce fotografías -cuatro en blanco y negro y ocho a colorcomponen la serie, la cual se centra en el estudio de dos desnudeces: la del zapallo, en toda su carnosidad interna y la de la modelo en su belleza madura, cuya edad se acerca a la que la fotógrafa tiene por entonces. ${ }^{2} \mathrm{La}$ verdura y la mujer conforman un solo cuerpo. La modelo transmite una fuerte personalidad, de mirada sugestiva, «[...] ella instintivamente se movía y yo le tomaba fotos [...]», señala Fusková. (Ilse Fusková, 2008) La propuesta fotográfica la podemos iniciar con la foto de Silvia Schmidt -escritora y amiga de Ilse Fusková- quien porta sobre su cabeza al vegetal.

La fotógrafa considera que la fertilidad de las mujeres está tanto en el vientre como en la mente,

es por ello que cuando decide exhibir estos trabajos en los talleres Brígida Rubio ${ }^{3}$ -ese mismo año de 1982- esta imagen es la seleccionada para el cartel de la exposición. En ella se relaciona al zapallo con la cabeza de la mujer, la oscuridad e irregularidades de la cáscara del vegetal dialogan con el pelo ondulado de Schmidt. Además, acompaña a la presentación de las obras, un breve poema de su autoría que se publica en la tarjeta de invitación. En él da a conocer su concepto de fertilidad femenina, así indica:

En el mercado siempre me deleita el zapallo abierto. Dentro de sus dorados y sutiles telones son escenarios para una liberadora fantasía. Y junto con la poderosa alineación de sus semillas, se tradujo para mí en la imagen de la fertilidad de la mujer.

Fértil con su vientre.

2 La modelo posaba frecuentemente para artistas tales como el pintor Raúl Soldi, y era conocida de Silvia Schmidt, amiga de Fusková, quien se la presenta a la fotógrafa.

3 La exposición fotográfica El Zapallo se organiza en los talleres Brígida Rubio de la ciudad de Buenos Aires los días 15 a 24 de octubre de 1982. 
Fértil con su mente.

Sus hijos y sus hijas y sus ideas pueden cambiar el mundo. (Fusková, 1982)

La verdura abierta, con todo su cuerpo interno en exhibición, puede ser interpretada como símbolo de vida. Fusková comenta que «[...] no veía la relación con la vagina. Había gente que se reía porque yo mostré eso en San Telmo en el ochenta y dos. Eso de que fuera una vagina, un útero me sucedió más tarde. [...] Esos trabajos porque siento que tienen varios niveles de lectura. [...] ¡Cómo a medida que pasan las cosas una puede ver desde otro lugar el trabajo propio!». (Ilse Fusková, 2008) La lente fotográfica captura los vínculos visuales y simbólicos existentes entre el cuerpo del vegetal y el femenino.

A nuestro entender, la foto en blanco y negro, la cual es seleccionada en 1986 para integrar la exposición internacional de fotografía Mujeres fotografían mujeres -organizada por la Volkshochschule de Munich ${ }^{4}$-, es la que logra capturar profundamente el concepto de fertilidad de Fusková. La modelo se encuentra sentada sobre el piso y lleva la verdura abierta en el lugar de su pubis, como si éste fuera aquél. Sus manos se unen en suave gesto sobre la cáscara. Los pechos quedan tenuemente ocultos entre la verdura y los brazos. Piernas y brazos enmarcan al zapallo. Posee una mirada concentrada en el propio placer de estar allí, sin dramatismos ni excesos, es la voluptuosidad del vegetal lo que en cierta forma hace las delicias de la figura. La luz fluye a través de la imagen, sin fuertes contrastes ni pronunciadas sombras. El contraste entre interior y exterior de las figuras convive conformando un cuerpo único y diferente, un otro cuerpo.

La serie El Zapallo logra poner en imágenes una profunda reflexión sobre la mirada de una mujer hacia el cuerpo de otra mujer en particular, y hacia el cuerpo femenino en general:

La mayoría de las mujeres en la cultura occidental nos vemos a través de la mirada distorsionada de una sociedad dominada por varones. Esto es verdad para todo nuestro ser y muy especialmente para la percepción que tenemos de

4 La muestra internacional estuvo integrada por 161 mujeres de 27 países, y se llevó a cabo desde el 3 de septiembre al 20 de octubre de 1986 en Múnich, luego itineró por varios países. 


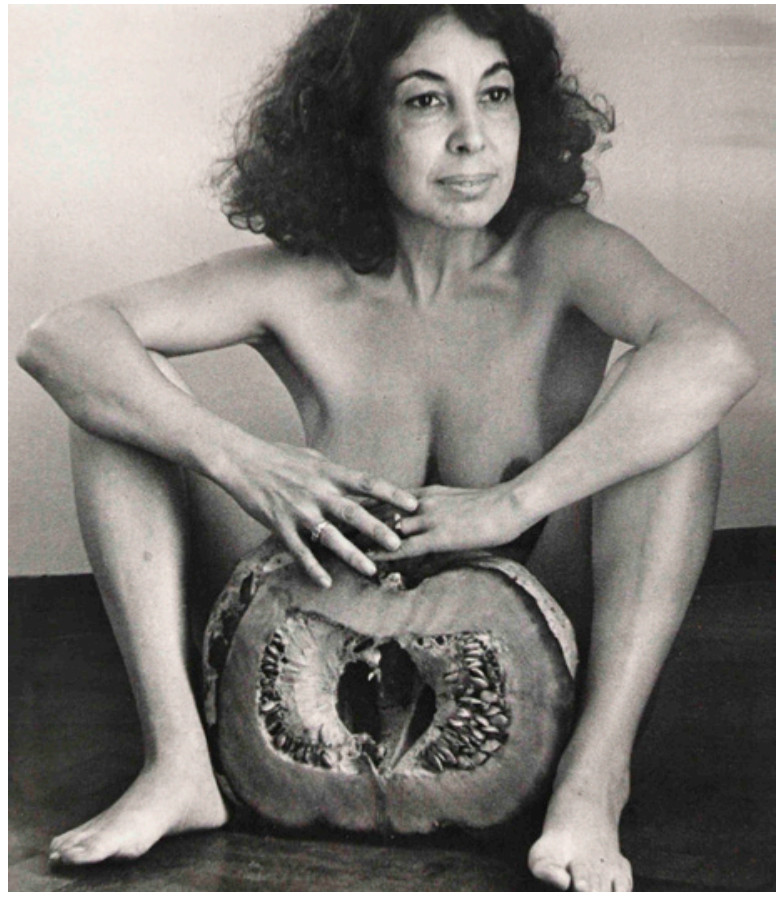

Imagen 6. Ilse Fusková. De la serie El zapallo, 1982, fotografía blanco y negro $35 \mathrm{~mm}$. (Archivo Ilse Fusková) nuestro propio cuerpo. (...) Yo pienso que el cuerpo de la mujer es objeto de deseo del macho, que ese cuerpo le fascina y también le da miedo. Sin embargo el cuerpo desnudo de la mujer, sin las contorsiones de la seducción, es una imagen prohibida. (...) La desnudez del cuerpo de la mujer es un derecho que nos es absolutamente negado. (Fusková and Marek, 1994: 42-43)

Años más tarde, teóricas feministas anglosajonas como Janet Wolff reflexionan al respecto: «Tenemos que preguntarnos qué significa esto para la práctica artística feminista ¿pueden las mujeres pintar los cuerpos de las mujeres? ¿Hay formas de subvertir o eludir los modos dominantes de representación? Y para las políticas corporales después de todo, ¿puede el cuerpo ser el lugar de crítica cultural?» (Wolff, 1990: 128) En relación con lo señalado, considero que los trabajos de Fusková van en esa dirección dado que buscan preguntarse y a la vez proponer en el campo visual imágenes contrahegemónicas de lo femenino: la desnudez de una mujer madura le otorga un papel central a la experiencia de vida dentro de la construcción de otras imágenes corporales a la vez que exhibe otras construcciones de belleza posibles. Además, la verdura abre a reflexiones sobre la sensualidad y la sexualidad: en su organicidad, en sus texturas, el zapallo construye diferentes recorridos visuales que desvían el lugar común de la mirada hetero-masculina hacia la genitalidad femenina. En el zapallo confluyen la fertilidad mental y biológica de las mujeres: ubicado sobre el vientre y apoyado sobre el piso, es el polo opuesto a la cabeza de la mujer, lugar que recibe y vuelve enviar su energía, sus saberes. Sin embargo, entiendo lo biológico como lo enuncia Wolff: «La biología siempre está superpuesta u mediada por la cultura y por las formas en que las mujeres experimentan sus propios cuerpos, dado que es en gran medida un ducto del proceso social y político.» (Wolff, 1990: 133)

En ese sentido, la cuestión del disciplinamiento del cuerpo femenino a través de mecanismos de ocultamiento gracias a las prácticas culturales, impacta en la representación de la genitalidad femenina, como lo advierte a finales de los años 70 Lisa Tickner: «La aceptación y reintegración de los genitales femeninos en el arte ha sido, por lo tanto, un gesto político, más que directamente erótico.» (Tickner, 1978: 
242) Sin dudas, la presencia de la genitalidad femenina en el arte es un gesto político al igual que la decisión de Fusková de escoger a una mujer adulta como modelo fotográfico, dada la escasez de este tipo de representaciones de lo femenino a través de los mass-media e incluso del propio ambiente fotográfico, en la Argentina de entonces. Si la experiencia se adquiere con los años, la presencia de una mujer adulta desnuda es símbolo del recorrido vivido y a la vez gesto político.

En consecuencia, ya que toda experiencia está mediada por el cuerpo, no debemos olvidar que éste es un lugar de inscripción social y de producción discursiva desde donde construimos nuestra identidad. Las imágenes son un factor de condensación de los discursos, a las vez que los crean y los representan. Por ello, desde los años sesenta, cuando las feministas comienzan a deconstruir profundamente el sistema patriarcal, uno de los ejes de sus críticas son los massmedia y su ecuación de ideal de belleza más objetualización femenina desde el deseo masculino para la manipulación consumista que desarrolla el capitalismo. (Millet, 1975: 53) La serie El zapallo permite a Ilse Fusková profundizar en su propia experiencia femenina. Tópicos como la naturaleza y la fertilidad cobran una magnitud física y mental en las fotografías a la vez que son una toma de conciencia política y social. Su experiencia personal fue vía de formulación estética a la vez que política.

\section{3.- Una búsqueda de acercarse a la identidad a través del autorretrato}

En 1983, pocos meses antes del final de la dictadura militar, las feministas continúan organizando actividades. Destacamos las Jornadas de la Creatividad Femenina -1, 2 y 3 de abril de 1983-, cuyo lema fue 'En toda mujer hay una creadora y en toda creadora hay una mujer' y el Segundo Congreso La Mujer en el Mundo Hoy -18 y 19 de mayo de 1983-. En el primer evento, la feminista Marta Miguelez plantea la fundación de un espacio de reunión para todas las mujeres. Gracias esta idea, el 13 de agosto de 1983 abre sus puertas Lugar de Mujer, donde se recibe a todas aquellas que desean intercambiar ideas y analizar problemáticas propias del género más allá de autodesignarse o no feministas. Algunas de sus fundadoras son: Ana Amado, María Luisa Bemberg, Alicia D'Amico, Narcisa Hirsch, Elizabeth Jelin, María Luisa Lerer, Lidia Marticorena, Marta Migueles, Hilda Rais, Graciela Sikos y Sara Torres. Sus objetivos son claros:

Porque vamos a reunirnos para hablar de nosotras, desarrollando el respeto y la solidaridad, revisando los modelos convencionales de vinculación social. Porque somos conscientes de la necesidad de un lugar permanente de encuentro. Porque queremos revisar los prejuicios y tabúes que nos desprestigian y nos desvalorizan. Porque queremos rever los modelos dentro de los cuales fuimos educadas. Porque pensamos que el autoritarismo, la rivalidad y la competitividad atentan contra un modo de vida creativo y auténtico. Porque sí. ¿Para qué? Para reflexionar sobre nuestra inserción en la sociedad; discutir acerca de nuestro cuerpo, sexualidad, afectos creatividad, vínculos, identidad.«(Sin Autor/a, 1983: 5) 
En Lugar de Mujer se realizan actividades, talleres, exposiciones artísticas, proyección de cine, y grupos de estudio. Allí se produce un juego de ida y vuelta entre el campo artístico local y el activismo feminista ya que artistas tales como Teresa Volco, Ilse Fusková, Josefina Quesada, o la misma Alicia D’Amico, llevan problemáticas y debates que enriquecen discusiones y propuestas, situación que origina un momento dorado del arte feminista argentino. En dicho lugar, en noviembre de 1983 Ilse Fusková expone la serie El zapallo.

Retomando las actividades planteadas durante las Jornadas de la Creatividad Femenina, durante el mes de abril de 1983, Alicia D'Amico lleva a cabo un taller dedicado a difundir los trabajos de grandes fotógrafas internacionales, su metodología consiste en interpretar las obras destacando el lenguaje empleado por ellas y las marcas de género presentes. Mayra Leciñana, una de las jóvenes asistentes a dicho taller, recuerda que allí descubre a la estadounidense Diane Arbus:

Mostraba cómo las mujeres se atrevían a fotografiar cosas diferentes, como Diane Arbus que fotografió lo monstruoso. Hablaba sobre las rupturas que fueron

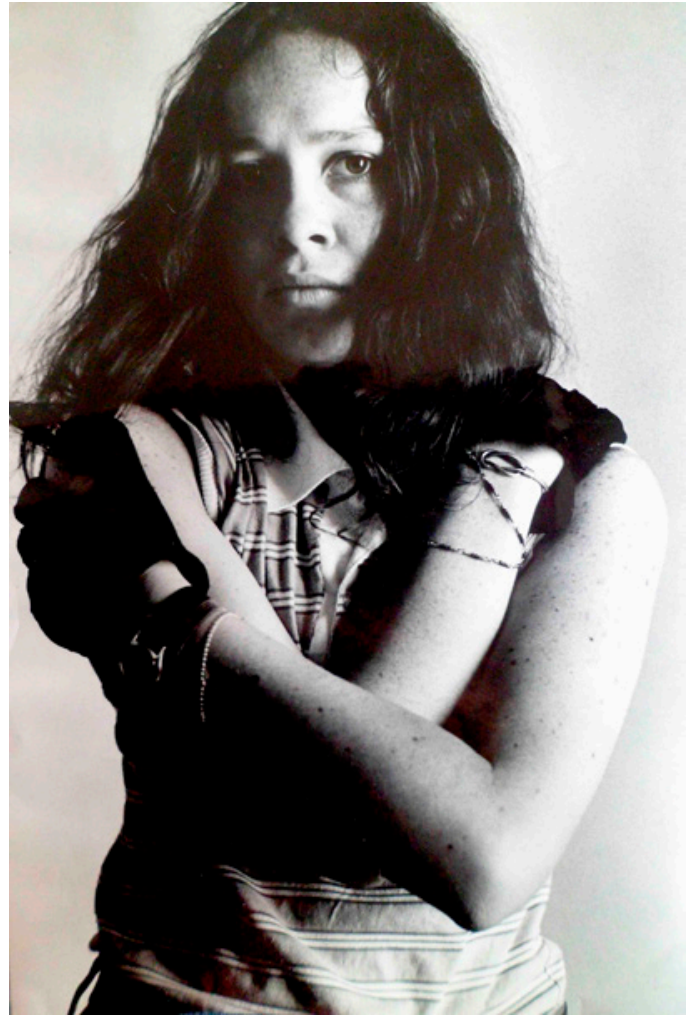

Imagen 7. Alicia D’Amico, Mayra Leciñana, Taller Autorretrato 1983. Copias de escaneos de negativo original reproducción de contactos de negativo original, $35 \mathrm{~mm}$. (Archivo Alicia D’Amico) haciendo las mujeres artistas. A la vez comparaba con algún fotógrafo hombre, como Pedro Luis Raota, quien por entonces hizo algunas fotografías de embarazadas que estaban de moda, D'Amico problematizaba la maternidad planteando que eso era una representación desde la mirada masculina. Decía cosas fuertes para mí que era muy joven y recién comenzaba a involucrarme con el feminismo. (Leciñana, 2016)

Allí mismo la fotógrafa dialoga con la psicóloga Graciela Sikos sobre una metodología de trabajo que le permita profundizar y refinar su proyecto Creación de la propia imagen. Esto da como resultado el formato taller que ponen ambas en práctica en Autorretrato. La primera experiencia que tienen es el 19 de mayo de 1983 en el Segundo Congreso La Mujer en el Mundo Hoy, realizado en el Teatro General San Martín (TGSM), luego hay una segunda instancia del mismo taller el día 26 de mayo en el estudio fotográfico D'Amico-Facio. En junio 
de ese mismo año se realiza otro taller en la casa de la fotógrafa Julie Weisz. En el II Encuentro Feminista Latinoamericano y del Caribe que se lleva a cabo en la ciudad de Lima (Perú) en el mes de julio de 1983, D’Amico y Sikos realizan nuevamente Autorretrato, lo que posibilita una exposición del material resultante en el Museo de Arte Moderno de Lima al año siguiente. Finalmente, en la recientemente inaugurada Lugar de Mujer se lleva a cabo este taller en octubre de 1983.

Todas las propuestas de Autorretrato plantean convocar a las mujeres para reflexionar sobre sí mismas, trabajar frente a espejos, desarrollar ejercicios corporales y de concentración que las conduzca a encontrar una imagen que las identifique. La democratización y rápida circulación de las imágenes trae aparejada una construcción imaginaria que es el resultado del diálogo constante entre lo que se considera el propio esquema corporal y los efectos que sobre éste tienen las miradas ajenas: los medios de comunicación, la observación de nuestros pares, entre otras/os. Esta dimensión especular detectada por las feministas de los setenta es la que se encuentra en la base del proyecto fotográfico de D'Amico al que dedica toda la década de los 80.

La dinámica del taller se organiza a través de dos encuentros que varían entre dos a cuatro horas de duración, dependiendo del grupo. Las bases teóricas empleadas vienen del campo de la psicología, específicamente del psicodrama y del teatro espontáneo. La finalidad de la actividad es alcanzar una autorreflexión sobre la identidad femenina que se pueda reflejar en imágenes. Así recuerda Graciela Sikos:

La idea de hacer retratos de mujeres era de Alicia y yo agregué la metodología de taller, es decir: hacer un trabajo corporal, hacer una relajación, llevar elementos para trabajar. Todos los objetos que se usaron en las fotos los llevé yo. Las mujeres escogían qué elemento usarían para posar, había un espejo ante el que se veían, determinaban la forma en que posarían, etc. y Alicia respetaba esa decisión. Luego, en el momento que presentábamos las fotos tomadas por Alicia, yo hacía que cada mujer dijera cómo se veía y qué se le ocurría ante su propia imagen a través de un cuestionario. Estábamos todas juntas pero las fotos se las dábamos de a una. Yo tomaba nota sobre lo que cada mujer iba contestando. La idea de las preguntas y de la escucha sobre qué les pasaba frente a la propia imagen fue mía. Eso es un autorretrato para mí, cuando vos te ves, cuando tenés la foto entre las manos y te reconocés, decís esta soy yo. (Sikos, 2016)

Mayra Leciñana, quien realiza uno de los talleres de Autorretrato, el dedicado a jóvenes y adolescentes, recuerda:

Al principio se planteaba un momento de distensión y de esparcimiento, caminábamos por ejemplo, con los ojos cerrados, se daba todo como para entrar en un clima de relajación. Después Graciela Sikos daba una charla planteando la idea de que uno puede construirse. Así es que nos proponía pensar cómo nos gustaría vernos, cómo nos percibimos. Ellas traían muchos elementos para que jugáramos a mostrarnos en un rol que se relacionara con cómo nos veíamos nosotras mismas: guantes, ropas, zapatos, mantos, encajes flores, corbatas. Una vez que protagonizábamos ese rol, Alicia nos tomaba una fotografía. Finalmente 
hacíamos un balance, una evaluación de cómo nos habíamos sentido con la imagen fotográfica que resultaba de este proceso de reflexión. (Leciñana, 2016)

Frente a una serie de sus propias fotografías, las participantes responden preguntas que Sikos elabora para acercarlas al imaginario corporal que cada una de ellas tiene. Estos relatos acompañan a las fotografías cada vez que son expuestas en espacios feministas como Lugar de Mujer o en instituciones artísticas como el ya citado Museo de Arte Moderno de Lima.

El periódico Tiempo Argentino publica algunas fotografías de Autorretrato en un artículo escrito por Sara Facio, así indica:

El autorretrato es, por definición, la búsqueda de la propia imagen. Todas las disciplinas artísticas (pintura, literatura, etcétera) tienen ejemplos magistrales. Estamos frente al autorretrato de una no-artista, de alguien que sólo busca su identidad, de crearse aunque la mano técnica pertenezca a «otra». Pero, atención, «otra» que la mira sin prejuicios, sin preconceptos, que es sólo el espejo. Y corresponde a la idea madre del autorretrato: autoconocimiento y aceptación no complaciente del yo. (Facio,1983: 2-3)

Una parte del material resultante es publicado en el periódico alfonsina, el cual comienza a circular en diciembre de 1983 con objeto de articular demandas e intereses de las mujeres con el contexto nacional. (Diz, 2010:1-16) Dicha publicación se hace eco de varias de las discusiones feministas así como de su impacto sobre la realidad política. (Bertúa; De Leone, 2009: 1-13) En el artículo que lleva por nombre Cómo Somos, Alicia D'Amico explica el sentido del taller de Autorretrato:

La hipótesis de trabajo sostiene que existe una mirada fotográfica femenina capaz de crear una nueva estética, redefiniendo el concepto tradicional de belleza; mirando de manera diferente, juzgando y creando de manera diferente. La mujer puede transformar la imagen de la mujer. (...) La identidad femenina pasa ahora a ser una cuestión de las mujeres.»(D'Amico 1984: 8) Dado que la identidad es una construcción y que las imágenes circulantes participan de un proceso de identificación, las mujeres deben construir imágenes que acompañen sus construcciones identitarias, diversas, múltiples y que pongan en jaque a la visualidad moldeada para el deseo masculino. D' Amico investiga cómo la libertad sobre el propio cuerpo y deseo femeninos lleva a crear otras representaciones, quizás con un grado mayor de autenticidad en relación con quien posa porque da cuenta de sus deseos, miedos, anhelos, a la vez que, busca sortear los idearios impuestos. Los géneros del retrato y el desnudo fueron centrales en su investigación.

En efecto, la fotógrafa analiza el impacto de la heteronormatividad sobre las construcciones de lo femenino. Aquellas mujeres concienciadas, que cuestionaron el sistema ideológico heterosexual, inician la creación de imágenes que van más allá de las reguladas por el patriarcado. La fotografía constituye un medio que permite el autoconocimiento. Así señala en un texto del año 1984: 

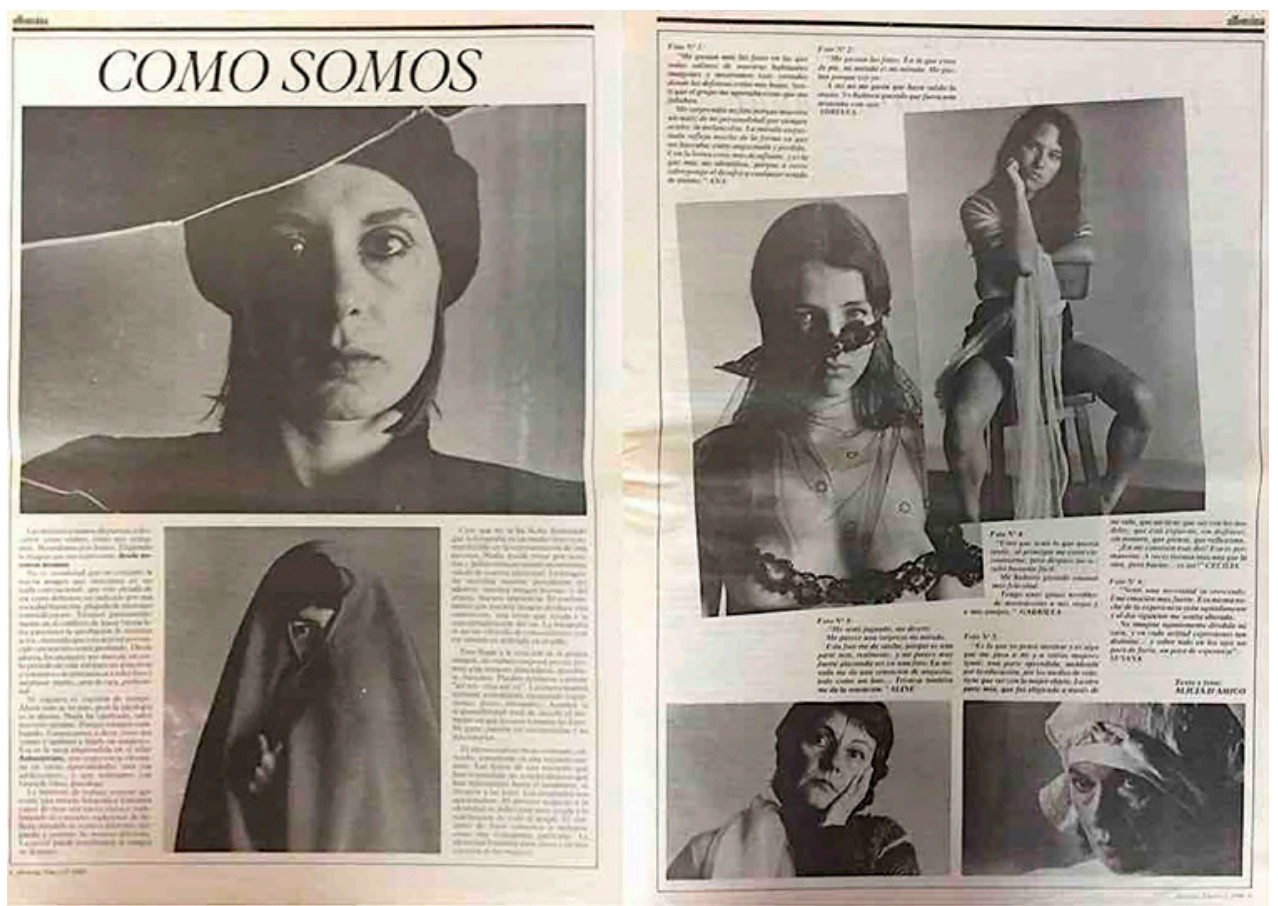

Imagen 8. Alicia D’Amico, Como Somos en alfonsina, 1984, pp. 8-9 (Archivo María Laura Rosa)

Las mujeres recibimos las pautas de nuestra identidad social a través de leyes, instituciones y costumbres. Se materializa a través de la imagen y la palabra. La reprobación social, el «que dirán», en cuanto nos apartamos de las condiciones establecidas, actúan como censores y contenedores de cualquier gesto independiente. Las mujeres estamos condicionadas por las imágenes que nos muestran de otras mujeres, inducidas desde el exterior por la sociedad. (D'Amico 1984: 52)

Dada la recuperación de las libertades en Argentina, es urgente que las mujeres piensen cómo quieren verse y ser vistas, cómo quieren nombrarse y ser nombradas. Hay fuertes esperanzas de cambio y para ello deben pensarse ellas mismas antes que ser pensadas por otros. Ellas buscan ser las protagonistas de sus propias vidas. Por entonces convergen varios factores que generan un ambiente propicio para reflexionar, revisar y reinscribir la subjetividad a la vez que poder protagonizar la vida dejando de lado la esclavitud de los mandatos. Algunos de ellos pueden ser: la salida de un régimen dictatorial genocida, con secuelas graves en los vínculos sociales, la madurez alcanzada por los movimientos feministas locales y la necesidad de socialización entre las mujeres, de recuperación de la comunicación física y afectiva.

Los comentarios de las integrantes de Autorretrato reflejan estas características del entorno. Es el caso de Ana: 
Me gustan más las fotos en las que todas salimos de nuestras habituales imágenes y mostramos esos costados en donde las defensas están más bajas. Sentí que el grupo me aportaba cosas que me faltaban. Me sorprendió mi foto porque muestra un matiz de mi personalidad siempre oculto: la melancolía. La mirada angustiada refleja mucho de la forma en que me buscaba; entre angustiada y perdida. Con la boina estoy más desafiante, y es la que más me identifica, porque a veces sobrepongo el desafío a cualquier estado de ánimo. ANA (D'Amico 1984: 53)

Ana es la profesora e intelectual Ana Amado (Santiago del Estero 1946-Buenos Aires 2016) ${ }^{5}$ quien recientemente regresa al país, tras el exilio junto a su marido Nicolás Casullo, primero en Caracas (1974-1975) y luego en México (1976-1983). Ella pertenece a esas mujeres curiosas e informadas que ansían insertarse en el clima de apertura cultural que por entonces vive la ciudad de Buenos Aires. La imagen refleja cierta melancolía en la mirada, tal como apunta la retratada, quizás por la experiencia nómade del exilio. La angustia sentida por cómo reconstruir la vida en una Argentina que busca revivir sin olvidar el pasado, es algo característico de muchas /os exiliadas/os de aquellos años. El corte fortuito que realiza la cámara al enrollar la película, es preservado por la fotógrafa como parte de la obra, y sin lugar a dudas, genera un marco misterioso para el rostro de Ana.

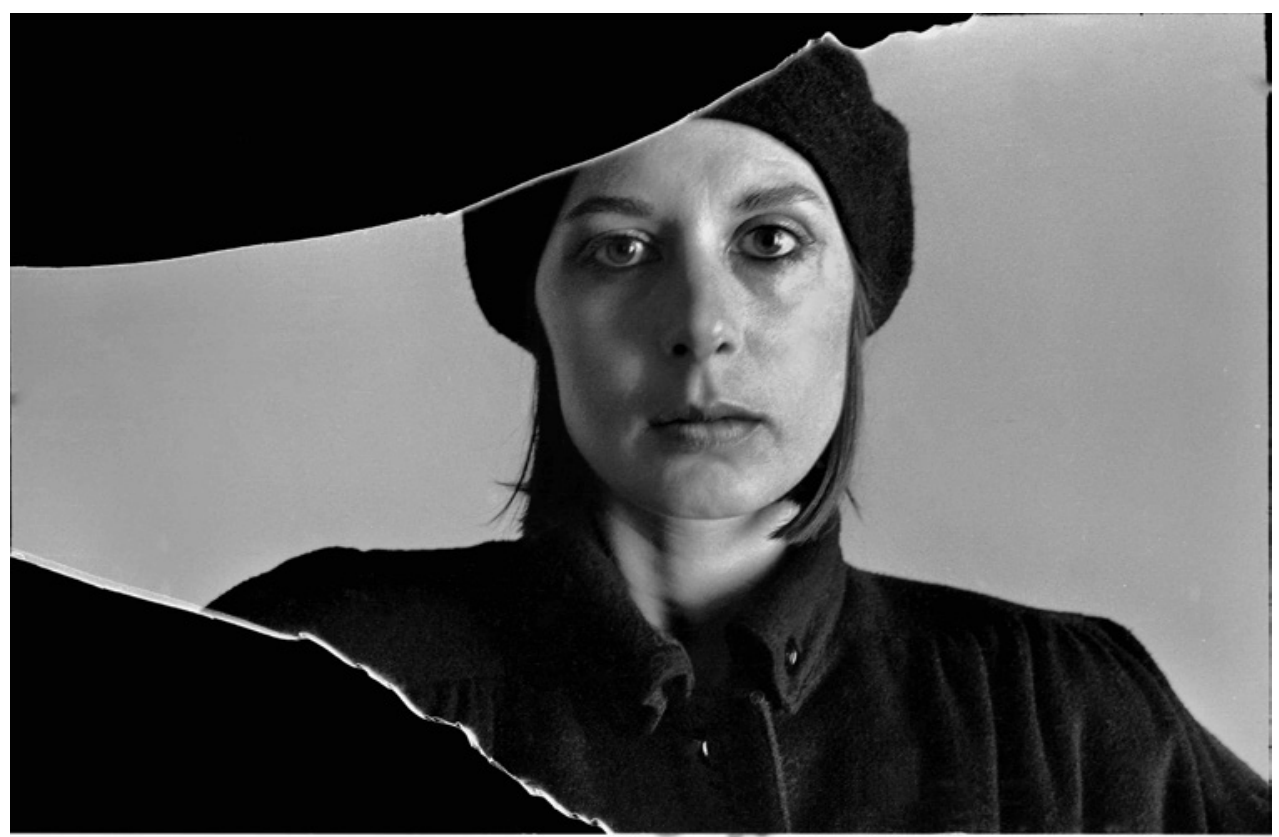

Imagen 9. Alicia D'Amico, Ana, 1984. Copias de escaneos de negativo original reproducción de contactos de negativo original, $35 \mathrm{~mm}$. (Archivo Alicia D'Amico)

5 Ana Amado fue corresponsal en Argentina de Fempress, Red Alternativa de Prensa Feminista para América Latina desde 1983 a 2001. 


\section{4.- Conclusiones}

Los proyectos fotográficos de Alicia D'Amico e Ilse Fusková están guiados por la preocupación de crear obras que reflejen las miradas de las mujeres hacia ellas mismas en diferentes momentos de sus vidas. Proponen otras poéticas corporales del género a la vez que realizan un análisis crítico sobre cómo operan las imágenes femeninas al uso, marcadas por la mirada deseante heterosexual masculina. Es en la propia dinámica de sus trabajos en donde queda en evidencia cómo la identidad se construye a través de comportamientos en los que las imágenes no son ajenas, por el contrario, cumplen un rol fundamental en la naturalización/ internalización de prácticas y comportamientos.

Estos proyectos bucean en la dimensión corporal de la experiencia femenina -desde perspectivas feministas- la cual ha sido negada durante siglos en el terreno de la representación visual. Dichas creaciones resultan de vital interés en la construcción de una genealogía visual feminista que recupere el cuerpo, las voces en primera persona, pero sobre todo, las miradas de las mujeres sobre sí mismas, anticipando investigaciones que plantearán las artistas argentinas en futuras décadas.

\section{Referencias / bibliografía}

Bertúa, Paula y Lucía De Leone (2009). «Identidades textuales y autorales en alfonsina: un juego de representaciones», en V.V.A.A. (2009) XXIII Jornadas de Investigación del Instituto de Literatura Hispanoamericana, Buenos Aires: Universidad de Buenos Aires, pp. 1-12.

Calvera, Leonor (1982). El género mujer, Buenos Aires: Editorial de Belgrano.

CAsAres, Giselle (1983). «Alicia D'Amico. Luz natural a las mujeres» en Tiempo Argentino. Suplemento La Mujer, 15 de marzo, pp. 1-2

D'Amico, Alicia (1985). Creación de la propia imagen [Documento inédito, Archivo Alicia D'Amico]

- (1984). «Salud, identidad y socialización. Relaciones con la imagen fotográfica» en V.V.A.A (1984) ¡Es preciso volar! Primer Encuentro Regional sobre la Salud de la Mujer, Bogotá: Ministerio de Salud.

— (1983). «Retrato de mujeres» en Fotomundo, N ${ }^{\circ} 178$, p.40.

DelPhy, Christine (1980) «The main enemy», en Feminist Issues No1, pp. 23-40

Diz, Tania (2010). «Tensiones, genealogías y feminismos en los '80. Un acercamiento a Alfonsina, primer periódico para mujeres», en Mora, 2010, pp. 1-16.

Exposición fotográfica creación de la propia imagen, 13 al 20 de mayo de 1985 [Folleto. Archivo Alicia D’Amico]

FACIO, Sara (1983). «La mirada femenina puede volverse un bumerán. Olvidándose de la versión que esperan los demás, varias mujeres ensayan sus primeros autorretratos fotográficos y aprenden a reconocer su verdadera imagen o a cambiarla», en Tiempo Argentino. Suplemento La Mujer, 13 de agosto, pp. 2-3, 
Firestone, Shulamith (1979). The Dialectic of Sex: The Case for Feminist Revolution, London:The Women's Press.

Fusková, Ilse y Claudina MAREK(1994). Amor de mujeres. El lesbianismo en la Argentina hoy, Buenos Aires: Planeta.

LARGUía, Isabel et al.(1972). La liberación de la mujer: Año cero, Buenos Aires: Granica. Millet, Kate (1975). Política sexual, México: Aguilar.

NARI, Marcela (2013). «No se nace feminista, se llega a serlo. Lecturas y recuerdos de Simone de Beauvoir en la Argentina, 1950 y 1990», en Halperin, Paula y Omar Acha, (2013): Cuerpos, género e identidades. Estudios de historias de género en Argentina, Buenos Aires: Ediciones del Siglo.

Sin Autor (1973) «Inquietud de entidades locales por la urgente emancipación femenina» en La Opinión, 26 de agosto, p.6.

Sin Autor (1983). « $¡$ Casa Tomada! Un lugar para cada una y cada una en su lugar» Tiempo Argentino. Suplemento La Mujer, 13 de agosto, p. 5.

Trebisacce, Catalina (2013). Memorias del feminismo de la ciudad de Buenos Aires en la primera mitad de la década del setenta, Universidad de Buenos Aires [manuscrito inédito].

TicKNeR, Lisa (1978). «The Body Politics: Female Sexuality \& Women Artists since 1970» en Art History, Vol. 2, p. 236-251.

Tickner, Lisa (1988). «Feminism, Art History and Sexual Differences» en Genders, No3, pp. 92-128.

WolfF, Janet (1990). Feminine Sentences. Essays on Women \& Culture, Cambridge: Blackwell Publisher.

\section{Entrevistas}

Entrevista a Leonor Calvera, 15 de agosto de 2019.

Entrevista a Mayra Leciñana, Buenos Aires, 15 de enero de 2016.

Entrevista a Graciela Sikos, Buenos Aires, 22 de septiembre de 2016.

Entrevista a Ilse Fusková, Buenos Aires, 17 de noviembre de 2004.

Entrevista a Ilse Fusková, Buenos Aires, 29 de agosto de 2008.

Entrevista a Ilse Fusková, Buenos Aires, 7 de agosto de 2008.

Recibido el 28 de junio de 2020 Aceptado el 14 de septiembre de 2020

BIBLID [1132-8231 (2020): 53-72] 